\title{
Spine stereotactic radiosurgery for the treatment of multiple myeloma
}

\author{
Jacob A. Miller, BS, ${ }^{1}$ Ehsan H. Balagamwala, MD, ${ }^{2}$ Samuel T. Chao, MD, ${ }^{2,3}$ Todd Emch, MD, ${ }^{4}$ \\ John H. Suh, MD, ${ }^{2,3}$ Toufik Djemil, PhD, ${ }^{5}$ and Lilyana Angelov, MD ${ }^{3,6}$
}

${ }^{1}$ Cleveland Clinic Lerner College of Medicine, ${ }^{2}$ Department of Radiation Oncology, ${ }^{3}$ Rose Ella Burkhardt Brain Tumor and Neuro-Oncology Center, ${ }^{4}$ Department of Diagnostic Radiology, and ${ }^{6}$ Department of Neurosurgery, Cleveland Clinic, Cleveland, Ohio; and ${ }^{5}$ Department of Radiation Oncology, Cleveland Clinic Florida, Weston, Florida

\begin{abstract}
OBJECTIVE The objective of this study was to define symptomatic and radiographic outcomes following spine stereotactic radiosurgery (SRS) for the treatment of multiple myeloma.

METHODS All patients with pathological diagnoses of myeloma undergoing spine SRS at a single institution were included. Patients with less than 1 month of follow-up were excluded. The primary outcome measure was the cumulative incidence of pain relief after spine SRS, while secondary outcomes included the cumulative incidences of radiographic failure and vertebral fracture. Pain scores before and after treatment were prospectively collected using the Brief Pain Inventory (BPI), a validated questionnaire used to assess severity and impact of pain upon daily functions.
\end{abstract}

RESULTS Fifty-six treatments (in 38 patients) were eligible for inclusion. Epidural disease was present in nearly all treatment sites (77\%). Moreover, preexisting vertebral fracture (63\%), thecal sac compression (55\%), and neural foraminal involvement (48\%) were common. Many treatment sites had undergone prior local therapy, including external beam radiation therapy (EBRT; $30 \%)$, surgery (23\%), and kyphoplasty (21\%). At the time of consultation for SRS, the worst, current, and average BPI pain scores at these treatment sites were 6,4 , and 4, respectively. The median prescription dose was 16 Gy in a single fraction. The median clinical follow-up duration after SRS was 26 months. The 6 - and 12-month cumulative incidences of radiographic failure were $6 \%$ and $9 \%$, respectively. Among painful treatment sites, $41 \%$ achieved pain relief adjusted for narcotic usage, with a median time to relief of 1.6 months. The 6 - and 12 -month cumulative incidences of adjusted pain progression were $13 \%$ and $15 \%$, respectively. After SRS, 1-month and 3-month worst, current, and average BPI scores all significantly decreased $(p<0.01)$. Vertebral fracture occurred following 12 treatments (21\%), with an $18 \%$ cumulative incidence of fracture at 6 and 12 months. Two patients $(4 \%)$ developed pain flare following spine SRS.

CONCLUSIONS This study reports the largest series of myeloma lesions treated with spine SRS. A rapid and durable symptomatic response was observed, with a median time to pain relief of 1.6 months. This response was durable among $85 \%$ of patients at 12 months following treatment, with $91 \%$ local control. The efficacy and minimal toxicity of spine SRS is likely related to the delivery of ablative and conformal radiation doses to the target. SRS should be considered with doses of 14-16 Gy in a single fraction for patients with multiple myeloma and limited spinal disease, myelosuppression requiring "marrow-sparing" radiation therapy, or recurrent disease after EBRT.

https://thejns.org/doi/abs/10.3171/2016.8.SPINE16412

KEY WORDS spine radiosurgery; multiple myeloma; vertebral metastasis; stereotactic body radiotherapy; oncology

$\mathrm{M}$ ULTIPLE myeloma is a malignant plasma cell neoplasm and the second most common hematological malignancy. $2,28,31$ The age-adjusted incidence of myeloma in the general population is 6 per 100,000 annually, with a $45 \% 5$-year survival rate. ${ }^{2,40}$ Overall surviv- al is more favorable with limited disease; however, more than $95 \%$ of patients with myeloma have diffuse disease at the time of initial diagnosis. With the advent of newer chemotherapeutic agents, the treatment of this disease is rapidly evolving. Since 2002 , the mortality rate has been

ABBREVIATIONS BPI = Brief Pain Inventory; EBRT = external beam radiation therapy; HD-MRI = high-definition MRI; HR = hazard ratio; KPS = Karnofsky Performance Scale; RTOG = Radiation Therapy Oncology Group; SRS = stereotactic radiosurgery.

SUBMITTED April 11, 2016. ACCEPTED August 4, 2016.

INCLUDE WHEN CITING Published online October 28, 2016; DOI: 10.3171/2016.8.SPINE16412. 
decreasing by $1 \%$ annually (www.seer.cancer.gov). ${ }^{42}$ As mortality declines due to improved systemic therapies, the prevalence of this disease increases, highlighting the importance of long-term quality of life.

The greatest morbidity among patients with myeloma stems from bone disease. ${ }^{30,40}$ At diagnosis, $80 \%$ of patients have radiographic evidence of osteolytic bone lesions. ${ }^{3,20,21,27,30}$ While patients may present with signs and symptoms of renal failure, hypercalcemia, or infection, patients most commonly present with bone pain emanating from the spine or ribs. Ultimately, the prevalence of bone pain approaches $100 \%$, requiring repeat surgical fixation, palliative radiotherapy, and narcotics. As a consequence of bone destruction in the spine, many patients suffer from vertebral fractures $(55 \%-70 \%)$ or neurological deficits caused by spinal cord or nerve root impingement (up to $30 \%$ ). 2,3,20,21

While chemotherapy remains the mainstay of treatment in myeloma, radiation therapy has an important role in palliation of symptoms and prophylaxis against cord compression. ${ }^{25,33}$ Because myeloma is inherently radiosensitive, patients have historically been treated with either hypofractionated or single-fraction external beam radiation therapy (EBRT).22,26,42 These treatments are generally well tolerated, with few complications and high rates of pain relief. ${ }^{38}$ As overall survival improves, many patients develop local failure at previously irradiated sites, requiring repeat radiotherapy. Although retreatment of most bone sites may be accomplished safely, retreatment of vertebral metastases requires careful evaluation to ensure tolerance of the spinal cord and/or cauda equina. ${ }^{8,39}$ Therefore, some patients may be well served with spine stereotactic radiosurgery (SRS), which offers the advantage of highly conformal radiation delivery that effectively targets the tumor while minimizing the dose to the spinal cord and adjacent vertebral bodies. ${ }^{1,17,41}$ Although this technique is most commonly used for the treatment of spinal metastases from solid tumors with local control rates of $80 \%-85 \%,{ }^{17,18}$ patients with myeloma and those with minimal spinal disease who previously underwent radiation treatment may be candidates for SRS. $17,18,33,35,41$

Given the efficacy of spine SRS for alleviation of pain and improvement in quality of life across a spectrum of pathologies, appropriate utilization of this modality for patients with myeloma should be considered..$^{5}$ Moreover, this technique may simultaneously prevent fracture progression and improve local control, especially among those with recurrence after conventional radiotherapy. ${ }^{6,19,23}$ There is a paucity of literature on the utilization of spine SRS in patients with myeloma. ${ }^{17,18,33}$ Therefore, in the present study, we report our experience with spine SRS for the treatment of vertebral metastases from myeloma.

\section{Methods \\ Patient Selection}

All patients who underwent spine SRS were included in a retrospective Institutional Review Board-approved registry. Only patients with confirmed pathological diagnoses of myeloma were included in the present study. Patients with less than 1 month of follow-up or concurrent second primary tumors were excluded. Primary indications for spine SRS were either symptomatic (pain, neurological deficits) or due to epidural extension of tumor evident on imaging. In general, patients with prior conventional radiotherapy, limited systemic disease burden, or myelosuppression necessitating "marrow-sparing" radiation therapy were eligible for SRS at this institution. In this cohort, $84 \%$ of patients met at least one of these primary indications for SRS. Extension of disease into the paraspinal soft tissues was not a contraindication for treatment.

\section{Spine SRS}

Patients eligible for SRS initially underwent CT simulation in the supine position. Those with disease at T-4 and above were immobilized in a 5-point thermoplastic head mask, while those with disease below T-4 were immobilized in a Bodyfix mold (Medical Intelligence; Elekta) with a vacuum bag for added immobilization. Simulation $\mathrm{CT}$ and high-definition MRI (HD-MRI) were obtained in $1.5-\mathrm{mm}$ slices. MRI sequences were then fused to the treatment-planning CT images using either BrainScan or iPlan software (Brainlab) or MIM (MIM Software Inc.). Target volumes were contoured using HD-MRI according to the bone involvement of the lesion as previously described in detail. ${ }^{35}$ In each case, the spinal cord was contoured approximately $5 \mathrm{~mm}$ above and below each target volume using HD-MRI. ${ }^{34,35}$ Treatment planning was performed using either BrainScan or iPlan software (Brainlab), and more recently, Pinnacle (Phillips). Image guidance during treatment delivery was achieved using cone-beam CT or orthogonal radiography and the ExacTrac system (Novalis). For single-fraction SRS, the spinal cord and cauda equina were constrained to 14-Gy and 16-Gy maximum point doses, respectively; the volume of spinal cord and cauda equina treated to $10 \mathrm{~Gy}$ and 12 Gy were both $<10 \%$. Patients were examined in the clinic 1-2 months after SRS and then every 3 months thereafter, with follow-up spine MRI and clinical examination at each follow-up.

\section{Outcome Measures and Statistics}

The primary outcome was the cumulative incidence of pain relief after spine SRS. ${ }^{13}$ Pain scores before and after treatment were prospectively collected using the Brief Pain Inventory (BPI), a validated questionnaire used to assess severity and impact of pain upon daily functions. ${ }^{4,11,14}$ The BPI is generally used in populations with chronic diseases such as osteoarthritis or cancer, and has been studied in the context of myeloma-associated vertebral fractures, metastatic bone disease, and SRS..$^{10,23,41}$ BPI scores were recorded as the "worst," "current," and "average" pain (ranging from 0 to 10) at each treatment site throughout clinical follow-up. Pain relief and symptomatic failure were adjusted for narcotic usage per Radiation Therapy Oncology Group (RTOG) study 0631. ${ }^{35}$ Any increase in narcotic utilization was considered pain progression. Pre-SRS BPI scores were compared with 1-month and 3-month post-SRS scores.

Secondary outcome variables included the cumulative incidences of vertebral fracture and radiographic failure after SRS. A neuroradiologist reviewed all follow-up spine 
MR images, which were compared with treatment-planning MR images to determine radiographic outcomes. Radiographic failure was defined as progression at the site of treatment as reported by a neuroradiologist and confirmed by a radiation oncologist or neurosurgeon. Post-SRS fracture was defined as new vertebral body height loss exceeding $20 \%$, or progressive height loss of $10 \%$. Wilcoxon signed-rank tests were used to compare paired continuous data. Kaplan-Meier analysis was used to determine estimates of overall survival, while cumulative incidence analysis was used to determine estimates of radiographic failure, pain relief, pain progression, relief of neurological deficits, and vertebral fracture. Differences in overall survival were compared using log-rank tests, while all other actuarial outcomes were compared with Gray's tests. ${ }^{15}$ Multivariate competing-risks regression was used to control for the following covariates, with death as a competing risk: Karnofsky Performance Scale (KPS) score, extent of spinal disease, systemic disease status, concurrent medical therapies, treatment location, number of treated levels, epidural disease, preexisting vertebral fracture, spinal cord compression, prior in-field irradiation, prior surgery, degree of pain, treatment volume, and maximum target dose. Covariates demonstrating association $(\mathrm{p} \leq 0.10)$ with outcome variables on univariate analysis were evaluated in a multivariate model. Covariate inclusion into the final multivariate model required a $\mathrm{p}$ value $\leq 0.10$. Analyses were conducted using the $\mathrm{R}$ statistical software package (R Core Team 2015; R Foundation for Statistical Computing).

\section{Results}

\section{Patient and Treatment Characteristics}

Fifty-six treatments (in 38 patients) were eligible for inclusion. The median patient age at the time of SRS was 59 years old (range 37-87 years old), and the median KPS score was 80 (range 50-90). Twenty-six patients (68\%) had extraspinal bone disease. More than half of the patients were receiving concurrent chemotherapy (63\%) or steroids (61\%; Table 1). At the time of SRS, $38 \%$ of patients were leukopenic, $66 \%$ of patients were anemic, $29 \%$ of patients were thrombocytopenic, and $73 \%$ of patients had a decrease in at least 1 cell line.

Characteristics of the 56 treatment sites are presented in Table 2. The majority (66\%) of treatment sites were located in the thoracic spine. Epidural disease was present in nearly all treatment sites (77\%). Moreover, preexisting vertebral fracture (63\%), thecal sac compression (55\%), and neural foraminal involvement (48\%) were common. Many treatment sites had undergone prior local therapy, including EBRT (30\%), surgery (23\%), and kyphoplasty (21\%). At the time of consultation for SRS, the worst, current, and average BPI pain score at these treatment sites was 6 , 4, and 4, respectively. Among 9 sites (16\%) associated with a neurological deficit, numbness/radicular pain was most common (66\%), followed by weakness $(55 \%)$ and bladder incontinence/retention (22\%). All but 3 sites $(5 \%)$ were treated with a single fraction. The median prescription dose was 14 Gy (range 10-24 Gy) in a single fraction (range 1-4 fractions).
TABLE 1. Patient characteristics

\begin{tabular}{|c|c|}
\hline Characteristic & Value $^{*}$ \\
\hline No. of patients & 38 \\
\hline Median age in yrs (range) & $59(37-87)$ \\
\hline Males (\%) & $22(58)$ \\
\hline Median KPS score (range) & $80(50-90)$ \\
\hline Median Neurologic Function Scale score (range) & $1(0-4)$ \\
\hline Prior smoker (\%) & $22(58)$ \\
\hline \multicolumn{2}{|l|}{ Comorbid disease (\%) } \\
\hline Mean $\mathrm{BMI} \pm \mathrm{SD}$ & $29 \pm 6$ \\
\hline Hypertension & $16(42)$ \\
\hline Hyperlipidemia & $8(21)$ \\
\hline Diabetes & $2(5)$ \\
\hline \multicolumn{2}{|l|}{ Spinal disease characteristics (\%) } \\
\hline Single-level disease & $7(18)$ \\
\hline Multilevel disease (2-5 VBs) & $14(37)$ \\
\hline Diffuse disease (>5 VBs) & $17(45)$ \\
\hline Extraspinal bone disease (\%) & $26(68)$ \\
\hline \multicolumn{2}{|l|}{ Concurrent medical therapies (\%) } \\
\hline Chemotherapy & $24(63)$ \\
\hline Steroids & $23(61)$ \\
\hline Bisphosphonates & $16(42)$ \\
\hline Median prior chemotherapy regimens (range) & $2(0-12)$ \\
\hline Median clinical follow-up in mos (range) & $26(1-78)$ \\
\hline Median radiographic follow-up in mos (range) & $17(1-67)$ \\
\hline Median overall survival in mos (range) & 26 \\
\hline
\end{tabular}

\section{Outcomes and Toxicity}

Clinical and radiographic outcomes after SRS are presented in Table 3. The median clinical follow-up duration after SRS was 26 months (range 1-67 months), while the median overall survival after SRS was 26 months (Fig. 1A). The 6- and 12-month cumulative incidences of radiographic failure were 6\% and 9\%, respectively (Fig. 1B). Among painful treatment sites, $41 \%$ achieved pain relief adjusted for narcotic usage (Fig. 2 upper). The median time to pain relief was 1.6 months. The 6 - and 12-month cumulative incidences of adjusted pain progression were $13 \%$ and $15 \%$, respectively (Fig. 2 lower). After SRS, 1 -month and 3-month worst ( $\mathrm{p}<0.01)$, current $(\mathrm{p}<0.01$ ), and average $(\mathrm{p}<0.01)$ BPI scores significantly decreased. Among 9 patients with neurological deficit at the time of treatment, 5 (56\%) achieved improvement following SRS, with a median time to relief of 1.2 months (Fig. 1D).

Vertebral fracture occurred following 12 treatments (21\%); 10 of 12 were due to progression of preexisting fractures, while 2 were de novo fractures (Fig. 1C). The 6- and 12-month cumulative incidences of fracture were each $18 \%$. Two (4\%) patients developed pain flare following spine SRS.

The incidences of post-SRS fracture in the up-front versus salvage settings were $21 \%$ versus $24 \%(\mathrm{p}=0.80)$, 
TABLE 2. Treatment site characteristics

\begin{tabular}{|c|c|}
\hline Characteristic & Value (\%) \\
\hline Treatments & 56 \\
\hline \multicolumn{2}{|l|}{ Location } \\
\hline Cervical & $4(7)$ \\
\hline Thoracic & $37(66)$ \\
\hline Lumbar & $12(21)$ \\
\hline Sacral & $3(5)$ \\
\hline \multicolumn{2}{|l|}{ No. of vertebral levels treated } \\
\hline 1 & $36(64)$ \\
\hline 2 & $13(23)$ \\
\hline$\geq 3$ & $7(13)$ \\
\hline \multicolumn{2}{|l|}{ Treatment site characteristics } \\
\hline Epidural disease & $43(77)$ \\
\hline Preexisting vertebral fracture & $35(63)$ \\
\hline Thecal sac compression & $31(55)$ \\
\hline Neural foraminal involvement & $27(48)$ \\
\hline Posterior elements disease & $22(39)$ \\
\hline Adjacent-segment disease & $18(32)$ \\
\hline Paraspinal extension & $16(29)$ \\
\hline Spinal cord compression & $8(14)$ \\
\hline \multicolumn{2}{|l|}{ Role of SRS } \\
\hline Primary & $29(52)$ \\
\hline Salvage & $19(34)$ \\
\hline Adjuvant & $8(14)$ \\
\hline \multicolumn{2}{|l|}{ Indications for SRS } \\
\hline Pain alone & $37(66)$ \\
\hline Asymptomatic* & $10(18)$ \\
\hline Pain w/ neurological deficit & $9(16)$ \\
\hline \multicolumn{2}{|l|}{ Prior local therapy } \\
\hline EBRT & $17(30)$ \\
\hline Any surgery & $13(23)$ \\
\hline Kyphoplasty & $12(21)$ \\
\hline Surgery w/ instrumentation & $4(7)$ \\
\hline \multicolumn{2}{|l|}{ Mean pre-SRS BPI score \pm SD } \\
\hline Worst pain & $6.1 \pm 3.1$ \\
\hline Current pain & $3.8 \pm 2.8$ \\
\hline Average pain & $4.0 \pm 3.0$ \\
\hline
\end{tabular}

Subtotals may exceed $100 \%$ if patients had, for example, multiple prior local therapies.

* Asymptomatic epidural disease or radiographic progression.

respectively. Comparable rates of adjusted pain relief ( $38 \%$ vs $41 \%, \mathrm{p}=0.85)$ and local failure $(15 \%$ vs $12 \%, \mathrm{p}=0.72)$ were also observed. However, the incidence of adjusted pain progression was lower in the up-front setting $(10 \%$ vs $29 \%, p=0.08$ ), although given the limited number of events, the origin of this difference is uncertain.

Multivariate analysis identified several significant independent predictors of radiographic failure and pain relief (Table 4). Prior in-field EBRT (hazard ratio [HR] $0.02, \mathrm{p}<0.01$ ) was protective against local failure, while larger target volumes (HR 1.46, $\mathrm{p}<0.01$ ) were associated with local progression. After adjusting for narcotic usage,
TABLE 3. Radiographic and symptomatic outcomes and toxicity

\begin{tabular}{|c|c|}
\hline Characteristic & Value (\%) \\
\hline Radiographic failure & $8(14)$ \\
\hline Median time to failure (mos) & Not reached \\
\hline Adjusted pain progression & $9(16)$ \\
\hline Median time to failure (mos) & Not reached \\
\hline Adjusted pain relief* & $19(41)$ \\
\hline Median time to relief (mos) & Not reached \\
\hline \multicolumn{2}{|l|}{ Mean 1-mo BPI score \pm SD } \\
\hline Worst pain & $3.3 \pm 3.0$ \\
\hline Current pain & $1.9 \pm 2.5$ \\
\hline Average pain & $2.4 \pm 2.4$ \\
\hline \multicolumn{2}{|l|}{ Mean 3-mo BPI score \pm SD } \\
\hline Worst pain & $3.1 \pm 3.4$ \\
\hline Current pain & $1.9 \pm 2.9$ \\
\hline Average pain & $2.2 \pm 3.0$ \\
\hline Neurological deficit relief† & $5(56)$ \\
\hline Median time to relief (mos) & 1.2 \\
\hline \multicolumn{2}{|l|}{ Post-SRS complications } \\
\hline Vertebral fracture $\ddagger$ & $12(21)$ \\
\hline Median time to fracture (mos) & Not reached \\
\hline Progressed fracture & $10(18)$ \\
\hline De novo fracture & $2(4)$ \\
\hline Pain flare & $2(4)$ \\
\hline Any local failure requiring retreatment & $5(9)$ \\
\hline EBRT & $3(5)$ \\
\hline SRS & $2(4)$ \\
\hline Characteristics of radiographic failure & $8(14)$ \\
\hline \multicolumn{2}{|l|}{ Site of failure } \\
\hline Vertebral body & $4(7)$ \\
\hline Epidural space & $3(5)$ \\
\hline Neural foramen & $2(4)$ \\
\hline Paraspinal & $1(2)$ \\
\hline
\end{tabular}

bisphosphonate use (HR 2.02, $\mathrm{p}<0.01$ ), spinal cord compression (HR 2.23, $\mathrm{p}<0.01$ ), and higher maximum target doses (HR 1.29, p < 0.01) were associated with more rapid pain relief. No independent predictors of pain progression or post-SRS fracture were identified after multivariate analysis.

\section{Discussion}

This series represents the largest of any prior investigation of SRS in the myeloma population. Outcomes for a series of 38 patients undergoing 56 treatments are reported, with a particular emphasis on pain relief and time to symptomatic and radiographic failure. We observed excellent radiographic and clinical outcomes following SRS: at 12 months, $85 \%$ of treatment sites were free from adjusted pain progression (Fig. 2 lower), with a radiographic control rate of $91 \%$ (Fig. 1B). Pain relief was rapid, with a 

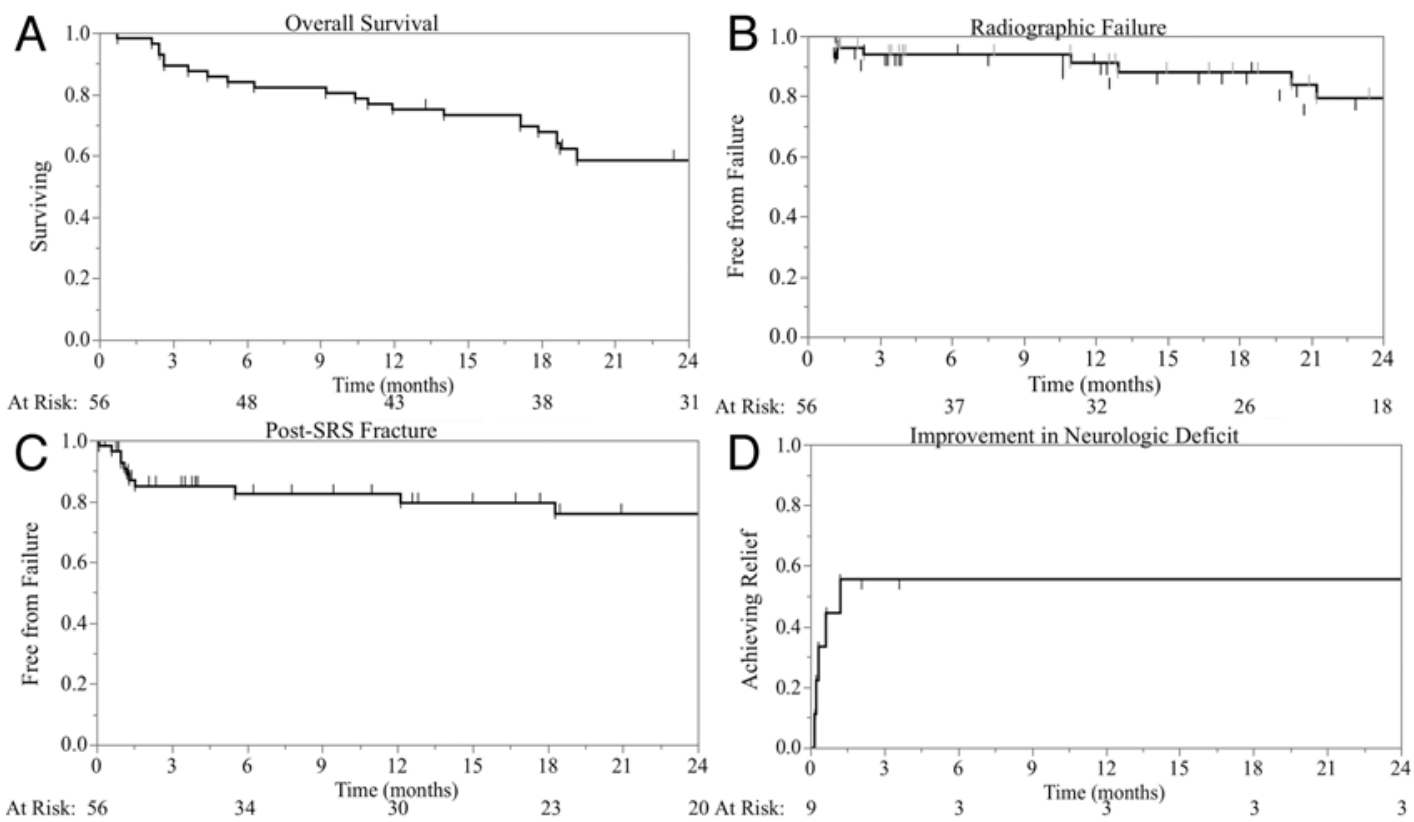

FIG. 1. Actuarial curves depicting proportion of cohort surviving (A), free from radiographic failure (B), free from post-SRS fracture (C), and achieving improvement of neurological deficit (D).

median time to relief of 1.6 months in a cohort of patients with extensive prior local therapy. Importantly, spine SRS was efficacious in the salvage setting, with prior in-field radiotherapy protective against local failure. These results demonstrate that rapid and durable pain relief is routinely achieved, and that few patients experience radiographic and symptomatic progression following spine SRS. The observed rate of pain control is comparable to pain control after conventional radiation (76\%) for any sites of bone disease (axial and extraaxial); more limited data are avail- able for pain control after conventional radiotherapy for spinal lesions exclusively. ${ }^{16}$ The low rate of pain progression and excellent radiographic control translated into a low retreatment rate (5 patients, 9\%). Among patients that required retreatment, $3(5 \%)$ underwent conventional EBRT (due to poor performance status) and 2 patients (4\%) underwent repeat spine SRS.

Data reported by Lecouvet et al..$^{19}$ suggest that radiation has a protective effect against subsequent fractures in the myeloma population, with an observed fracture incidence
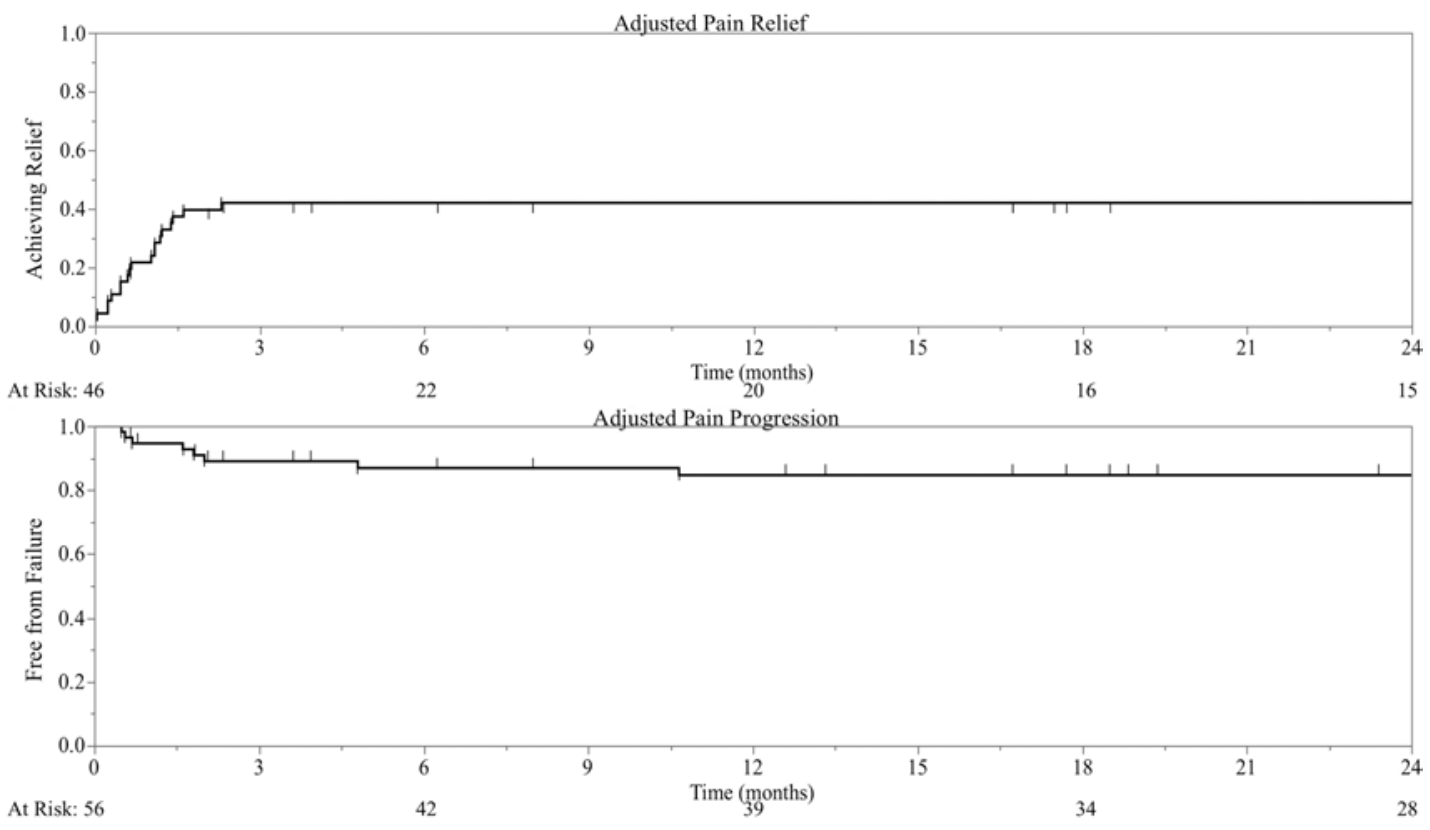

FIG. 2. Actuarial curves depicting proportion of cohort achieving adjusted symptomatic relief (upper) and free from adjusted symptomatic failure (lower). 
TABLE 4. Multivariate competing-risks regression analysis

\begin{tabular}{|c|c|c|c|c|c|c|c|c|}
\hline \multirow[b]{3}{*}{ Covariates } & \multicolumn{4}{|c|}{ Time to Radiographic Failure } & \multicolumn{4}{|c|}{ Time to Adjusted Pain Relief } \\
\hline & \multirow{2}{*}{$\begin{array}{c}\text { Univariate } \\
\text { p Value }\end{array}$} & \multicolumn{3}{|c|}{ Multivariate } & \multirow{2}{*}{$\begin{array}{c}\text { Univariate } \\
\text { p Value }\end{array}$} & \multicolumn{3}{|c|}{ Multivariate } \\
\hline & & $p$ Value & $H R$ & $95 \% \mathrm{Cl}$ & & $p$ Value & $\mathrm{HR}$ & $95 \% \mathrm{Cl}$ \\
\hline KPS score* & 0.15 & 0.15 & 2.08 & $0.78-7.51$ & 0.62 & & & \\
\hline BPI current pain & $<0.01$ & 0.52 & & & 0.65 & & & \\
\hline Bisphosphonate use & 0.58 & & & & 0.03 & $<0.01$ & 2.02 & $1.24-5.53$ \\
\hline Epidural disease & 0.70 & 0.16 & 4.74 & $0.55-85.68$ & 0.74 & & & \\
\hline Spinal cord compression & 0.72 & & & & 0.02 & $<0.01$ & 2.23 & $1.34-3.59$ \\
\hline Prior kyphoplasty & 0.19 & 0.86 & & & 0.26 & & & \\
\hline Prior fracture & 0.02 & 0.79 & & & 0.72 & & & \\
\hline Prior radiotherapy at site & 0.14 & $<0.01$ & 0.02 & $0.01-0.34$ & 0.96 & & & \\
\hline Max target dose (Gy) & 0.19 & 0.12 & 1.39 & $0.91-2.19$ & 0.07 & $<0.01$ & 1.29 & $1.11-1.49$ \\
\hline Target volume $\left(\mathrm{cm}^{3}\right)^{\star}$ & $<0.01$ & $<0.01$ & 1.46 & $1.19-1.99$ & 0.26 & & & \\
\hline
\end{tabular}

$\mathrm{Cl}=$ confidence interval.

Boldface type indicates statistical significance.

* Per 10-unit change.

of 5\% in patients who underwent radiation and $20 \%$ in patients who did not. However, high-dose radiation may also induce fractures. ${ }^{37} \mathrm{Jin}$ et al. suggested that these fractures may be related to the collapse of bone into the tumor cavity after ablation..$^{17}$ To protect against vertebral collapse, Chen et al. highlight the complementary roles of radiation and vertebral augmentation in the setting of multiple myeloma-associated vertebral fractures., ${ }^{7,42}$

Characterizing the natural history of myeloma fractures is challenging, as many patients present with fractures of varying severity and undergo radiation treatment to fracture sites. ${ }^{21,27}$ In the present cohort, $63 \%$ of patients had preexisting in-field vertebral compression fractures at the time of SRS, highlighting the osteolytic disease process of myeloma. Following SRS, 12 vertebral fractures occurred $(21 \%)$, of which nearly all $(n=10)$ were progressed fractures. This suggests that SRS rarely (4\%) induces de novo fractures in this population at this prescription dose, with preexisting fractures representing an obvious risk factor. Our fracture rate is lower than reports in several studies, and is likely due to a lower median prescription dose (14 Gy) used in treating myeloma patients at our institution. ${ }^{37}$ In a large multiinstitutional investigation of 410 spinal segments treated with SRS, the incidence of vertebral fracture was $14 \%$ (7\% de novo). ${ }^{37}$ The authors observed a significantly increased rate of fracture with single-fraction doses above $20 \mathrm{~Gy}$, as well as with lytic lesions, prior vertebral fracture, and spinal deformity. In a separate single-institution investigation including 167 fractionated SRS treatments, the incidence of fracture was $11 \%$ (7\% de novo). ${ }^{12}$ Given the excellent local control and modest treatment-related toxicity observed, the benefit of fractionated SRS would likely be marginal for improving safety. However, we would encourage limiting the prescription dose to 14-16 Gy given the radiosensitive nature of this disease.

There are limited comparative data to support the efficacy of prophylactic vertebral augmentation in combination with SRS, particularly for symptomatic end points. In this investigation, $21 \%$ of treatment sites underwent verte- bral augmentation prior to SRS, and the incidence of SRSrelated fracture was relatively low; accordingly, routine prophylactic vertebral augmentation may offer marginal benefit. Because the majority of observed fractures were progressive (83\%), vertebral augmentation may potentially be considered in a subset of patients with preexisting fractures (35 sites, $63 \%$ of cohort). However, among these 35 sites, only $10(29 \%)$ progressed after SRS. Accordingly, the number needed to treat to prevent 1 radiographic progressed fracture is approximately 3 . Further, as many postSRS fractures are asymptomatic, the perioperative morbidity and cost effectiveness of routine prophylactic vertebral augmentation requires evaluation in a larger study. Notably, concurrent steroid utilization at the time of SRS did not increase the risk for post-SRS fracture.

While fracture is the chief late toxicity following spine SRS, pain flare represents a common acute toxicity. In this series, only 2 treatments (4\%) resulted in the development of pain flare, which resolved rapidly with steroids. Prospective data suggest that the incidence of pain flare is approximately $10 \%-20 \%$ following spine SRS. ${ }^{29}$ Randomized trials have identified the utility of prophylactic steroids against pain flare following irradiation of bone metastases. ${ }^{9}$ Accordingly, the incidence of pain flare in this study may be low secondary to the use of dexamethasone in myeloma chemotherapeutic regimens. Indeed, $61 \%$ of patients received steroids at the time of SRS.

Multivariate modeling revealed several variables that were associated with pain relief. Of note, use of bisphosphonates augmented pain relief (HR 2.02, p < 0.01), further highlighting their efficacy in control of skeletal-related events and pain. ${ }^{24}$ Indeed, prior investigations have suggested a survival benefit with the use of these agents in multiple myeloma. ${ }^{6}$ In addition, those with spinal cord compression experienced more rapid adjusted pain relief (HR 2.23, p < 0.01). Accordingly, patients with epidural disease and cord compression may expect rapid decompression with SRS (Fig. 3), while those with chronic mechanical pain unrelated to cord compression may expect a smaller benefit. Although prescription dose had no impact 

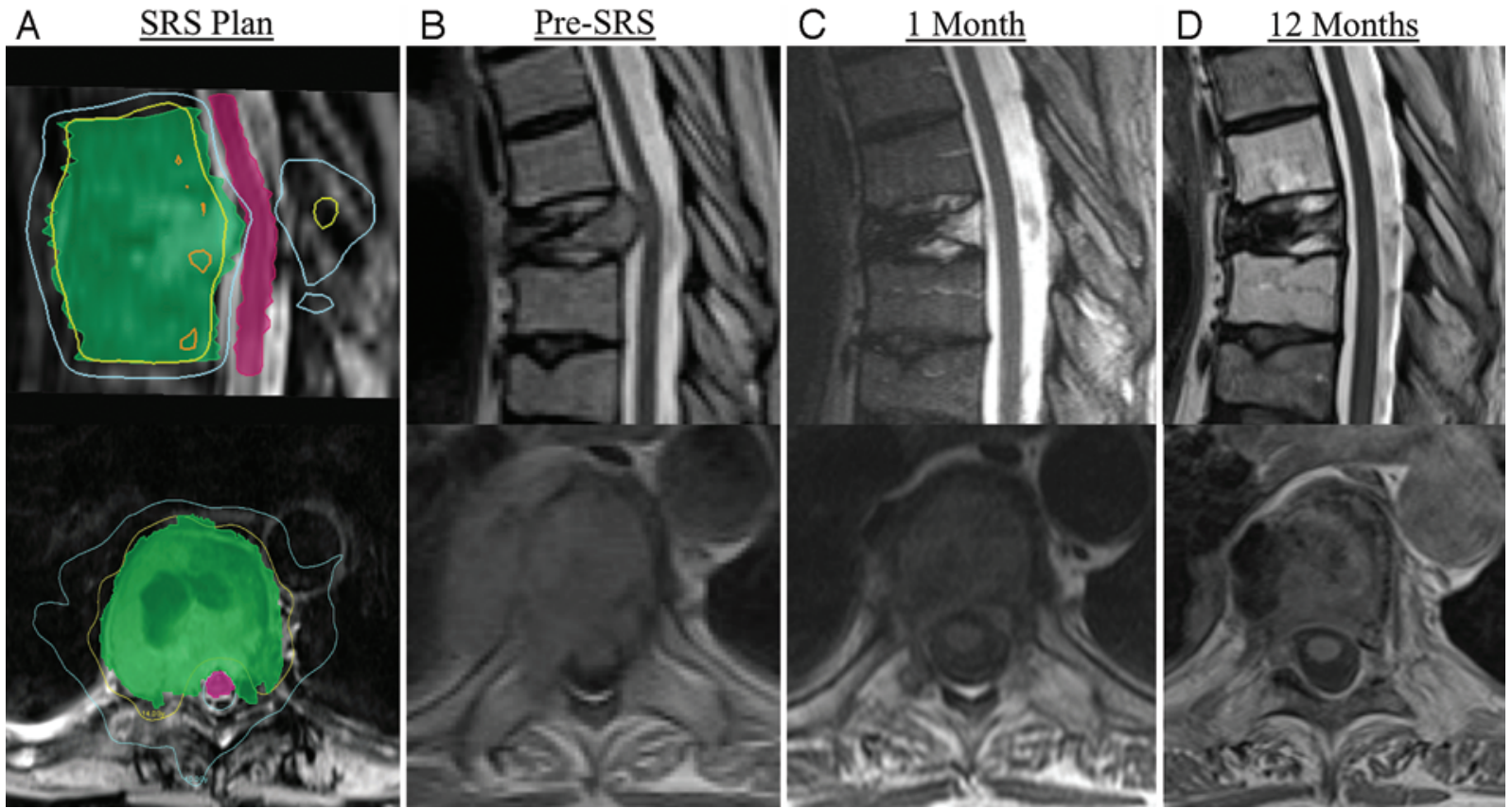

FIG. 3. Sagittal (upper) and axial (lower) images of a T7-9 SRS dose plan (A) demonstrating spinal cord planning risk volume (pink), clinical target volume (green), prescription isodose line (yellow line), 10-Gy isodose line (blue line), and 16-Gy isodose line (orange line). Sagittal T2-weighted (upper) and axial noncontrast T1-weighted (lower) MR images through the thoracic spine before SRS (B), 1 month after SRS (C), and 12 months after SRS (D), demonstrating resolution of the epidural disease with no associated significant vertebral body height loss in a previously untreated patient. Figure is available in color online only.

on pain response, multivariate analysis demonstrated that maximum target dose was associated with rapid time to pain relief (HR 1.29, $\mathrm{p}<0.01$ ), and did not significantly impact future fracture risk. This may suggest a role for relaxing homogeneity constraints.

There is a paucity of data reporting spine SRS outcomes in multiple myeloma. Jin et al. conducted a study of 31 myeloma epidural lesions (in 24 patients) compressing the spinal cord, treated using SRS. ${ }^{17}$ After a median follow-up of 11 months, overall pain control was 86\%, complete symptom relief was achieved in 54\%, and radiographic response was $81 \%$ at 3 months. The authors supported the use of SRS in myeloma-associated spinal cord compression, citing the impressive radiographic and clinical improvements after treatment, as well as the relative convenience over surgery or fractionated radiotherapy. In a smaller study conducted by Rock et al. that included 4 patients with myeloma treated with radiosurgery, the overall neurological deterioration after SRS was just 8\%.33 However, these studies were more limited in scope and did not use multivariate methods to identify predictors of treatment response.

There are a number of limitations that must be considered with the present study. As a retrospective investigation, these data are subject to greater measurement bias, selection bias, and confounding than prospective studies. However, no prospective investigations have been conducted investigating this technique in multiple myeloma, with RTOG study 0631 specifically excluding patients with myeloma. ${ }^{35,36}$ The size of this study was relatively small, limiting the generalizability and utility of multivariate regression. In particular, a limited number of patients presented with a neurological deficit, limiting the capacity to draw conclusions regarding reversal of such deficits. However, with the exception of prescription dose and fractionation, all technique-related variables were consistent among treatments in an effort to minimize treatment variability. As with most palliative investigations, characterization of symptomatic response is challenging given the subjectivity and heterogeneity of patient perspectives. In an effort to combat this challenge, we used prospectively collected validated tools such as the BPI in an attempt to standardize monitoring during clinical follow-up.

The strengths of this study lie in the consistency of treatment delivered, the utilization of both primary and secondary outcome variables for monitoring objective (e.g., survival, fracture) and subjective (e.g., pain) end points, and the incorporation of multivariate modeling to identify variables associated with favorable and unfavorable outcome. Based upon these results, our study suggests that the utilization of spine SRS in the myeloma population is a safe and effective means for palliating pain and neurological deficits.

\section{Conclusions}

In this study we report a series of 56 myeloma lesions treated with spine SRS, with specific attention to pain relief. A rapid and durable symptomatic response was observed, with a median time to pain relief of 1.6 months. This response was durable in $85 \%$ of patients at 12 months following treatment, with $91 \%$ local control. Our study also demonstrates minimal toxicity in this population. The efficacy and minimal toxicity of spine SRS is likely related 
to the delivery of ablative and conformal radiation doses to the target. As a radiosensitive disease, SRS should be considered with doses of 14-16 Gy in a single fraction for patients with multiple myeloma and limited spinal disease, in patients with myelosuppression requiring "marrowsparing" radiation therapy, or in patients with recurrent disease after conventional radiotherapy.

\section{References}

1. Alafaci C, Grasso G, Conti A, Caffo M, Salpietro FM, Tomasello F: Cyberknife radiosurgery for cranial plasma cell tumor. Turk Neurosurg 24:272-275, 2014

2. Anderson KC: Multiple myeloma: a clinical overview. Oncology (Williston Park) 25 (25 Suppl 2):3-9, 2011

3. Angtuaco EJC, Fassas ABT, Walker R, Sethi R, Barlogie B: Multiple myeloma: clinical review and diagnostic imaging. Radiology 231:11-23, 2004

4. Atkinson TM, Rosenfeld BD, Sit L, Mendoza TR, Fruscione M, Lavene D, et al: Using confirmatory factor analysis to evaluate construct validity of the Brief Pain Inventory (BPI). J Pain Symptom Manage 41:558-565, 2011

5. Balagamwala EH, Suh JH, Reddy CA, Angelov L, Djemil T, Magnelli A, et al: Higher dose spine stereotactic body radiation therapy is associated with improved pain control in radiosensitive histologies. Int J Radiat Oncol Biol Phys 84 (3 Suppl):S632-S633, 2012 (Abstract)

6. Berenson JR, Lichtenstein A, Porter L, Dimopoulos MA, Bordoni R, George S, et al: Long-term pamidronate treatment of advanced multiple myeloma patients reduces skeletal events. J Clin Oncol 16:593-602, 1998

7. Chen LH, Hsieh MK, Niu CC, Fu TS, Lai PL, Chen WJ: Percutaneous vertebroplasty for pathological vertebral compression fractures secondary to multiple myeloma. Arch Orthop Trauma Surg 132:759-764, 2012

8. Chow E, Meyer RM, Chen BE, van der Linden YM, Roos D, Hartsell WF, et al: Impact of reirradiation of painful osseous metastases on quality of life and function: a secondary analysis of the NCIC CTG SC.20 randomized trial. J Clin Oncol 32:3867-3873, 2014

9. Chow E, Meyer RM, Ding K, Nabid A, Chabot P, Wong P, et al: Dexamethasone in the prophylaxis of radiation-induced pain flare after palliative radiotherapy for bone metastases: a double-blind, randomised placebo-controlled, phase 3 trial. Lancet Oncol 16:1463-1472, 2015

10. Cleeland CS: The measurement of pain from metastatic bone disease: capturing the patient's experience. Clin Cancer Res 12:6236s-6242s, 2006

11. Cleeland CS, Ryan KM: Pain assessment: global use of the Brief Pain Inventory. Ann Acad Med Singapore 23:129138, 1994

12. Cunha MVR, Al-Omair A, Atenafu EG, Masucci GL, Letourneau D, Korol R, et al: Vertebral compression fracture (VCF) after spine stereotactic body radiation therapy (SBRT): analysis of predictive factors. Int J Radiat Oncol Biol Phys 84:e343-e349, 2012

13. Dignam JJ, Kocherginsky MN: Choice and interpretation of statistical tests used when competing risks are present. J Clin Oncol 26:4027-4034, 2008

14. Ferreira KA, Teixeira MJ, Mendonza TR, Cleeland CS: Validation of brief pain inventory to Brazilian patients with pain. Support Care Cancer 19:505-511, 2011

15. Fine JP, Gray RJ: A proportional hazards model for the subdistribution of a competing risk. J Am Stat Assoc 94:496509, 1999

16. Hunter GK, Balagamwala EH, Koyfman SA, Bledsoe T, Sheplan LJ, Reddy CA, et al: The efficacy of external beam radiotherapy and stereotactic body radiotherapy for painful spinal metastases from renal cell carcinoma. Pract Radiat Oncol 2:e95-e100, 2012

17. Jin R, Rock J, Jin JY, Janakiraman N, Kim JH, Movsas B, et al: Single fraction spine radiosurgery for myeloma epidural spinal cord compression. J Exp Ther Oncol 8:35-41, 2009

18. Joaquim AF, Ghizoni E, Tedeschi H, Pereira EB, Giacomini LA: Stereotactic radiosurgery for spinal metastases: a literature review. Einstein (Sao Paulo) 11:247-255, 2013

19. Lecouvet F, Richard F, Vande Berg B, Malghem J, Maldague B, Jamart J, et al: Long-term effects of localized spinal radiation therapy on vertebral fractures and focal lesions appearance in patients with multiple myeloma. Br J Haematol 96: 743-745, 1997

20. Lecouvet FE, Malghem J, Michaux L, Michaux JL, Lehmann F, Maldague BE, et al: Vertebral compression fractures in multiple myeloma. Part II. Assessment of fracture risk with MR imaging of spinal bone marrow. Radiology 204:201205, 1997

21. Lecouvet FE, Vande Berg BC, Maldague BE, Michaux L, Laterre E, Michaux JL, et al: Vertebral compression fractures in multiple myeloma. Part I. Distribution and appearance at MR imaging. Radiology 204:195-199, 1997

22. Leigh BR, Kurtts TA, Mack CF, Matzner MB, Shimm DS: Radiation therapy for the palliation of multiple myeloma. Int J Radiat Oncol Biol Phys 25:801-804, 1993

23. Mendoza TR, Koyyalagunta D, Burton AW, Thomas SK, Phan MHV, Giralt SA, et al: Changes in pain and other symptoms in patients with painful multiple myeloma-related vertebral fracture treated with kyphoplasty or vertebroplasty. J Pain 13:564-570, 2012

24. Mhaskar R, Redzepovic J, Wheatley K, Clark OAC, Miladinovic B, Glasmacher A, et al: Bisphosphonates in multiple myeloma: a network meta-analysis. Cochrane Database Syst Rev 5:CD003188, 2012

25. Mikhael JR, Dingli D, Roy V, Reeder CB, Buadi FK, Hayman SR, et al: Management of newly diagnosed symptomatic multiple myeloma: updated Mayo Stratification of Myeloma and Risk-Adapted Therapy (mSMART) Consensus Guidelines 2013. Mayo Clin Proc 88:360-376, 2013 (Erratum in Mayo Clin Proc 88:777, 2013)

26. Mill WB: Radiation therapy in multiple myeloma. Radiology 115:175-178, 1975

27. Miller JA, Bowen A, Morisada MV, Margetis K, Lubelski D, Lieberman IH, et al: Radiologic and clinical characteristics of vertebral fractures in multiple myeloma. Spine J Off J North Am Spine Soc: 2015

28. Palumbo A, Anderson K: Multiple myeloma. N Engl J Med 364:1046-1060, 2011

29. Pan HY, Allen PK, Wang XS, Chang EL, Rhines LD, Tatsui $\mathrm{CE}$, et al: Incidence and predictive factors of pain flare after spine stereotactic body radiation therapy: secondary analysis of phase 1/2 trials. Int J Radiat Oncol Biol Phys 90:870876,2014

30. Poon M, Zeng L, Zhang L, Hsiao J, Wong E, Lam H, et al: Incidence of skeletal morbidity rates over time in patients with multiple myeloma-related bone disease as reported in randomized trials employing bone-modifying agents. J Comp Eff Res 2:69-76, 2013

31. Raab MS, Podar K, Breitkreutz I, Richardson PG, Anderson KC: Multiple myeloma. Lancet 374:324-339, 2009

32. Raje N, Anderson KC: Multiple myeloma. Curr Treat Options Oncol 1:73-82, 2000

33. Rock JP, Ryu S, Shukairy MS, Yin FF, Sharif A, Schreiber F, et al: Postoperative radiosurgery for malignant spinal tumors. Neurosurgery 58:891-898, 2006

34. Ryu S, Jin JY, Jin R, Rock J, Ajlouni M, Movsas B, et al: Partial volume tolerance of the spinal cord and complications of single-dose radiosurgery. Cancer 109:628-636, 2007

35. Ryu S, Pugh SL, Gerszten PC, Yin FF, Timmerman RD, 
Hitchcock YJ, et al: RTOG 0631 Phase II/III study of imageguided stereotactic radiosurgery for localized (1-3) spine metastases: phase II results. Int J Radiat Oncol Biol Phys 81:S131-S132, 2011

36. Ryu S, Pugh SL, Gerszten PC, Yin FF, Timmerman RD, Hitchcock YJ, et al: RTOG 0631 phase $2 / 3$ study of image guided stereotactic radiosurgery for localized (1-3) spine metastases: phase 2 results. Pract Radiat Oncol 4:76-81, 2014

37. Sahgal A, Atenafu EG, Chao S, Al-Omair A, Boehling N, Balagamwala EH, et al: Vertebral compression fracture after spine stereotactic body radiotherapy: a multi-institutional analysis with a focus on radiation dose and the spinal instability neoplastic score. J Clin Oncol 31:3426-3431, 2013

38. Talamo G, Dimaio C, Abbi KKS, Pandey MK, Malysz J, Creer $\mathrm{MH}$, et al: Current role of radiation therapy for multiple myeloma. Front Oncol 5:40, 2015

39. van der Linden YM, Lok JJ, Steenland E, Martijn H, van Houwelingen H, Marijnen CAM, et al: Single fraction radiotherapy is efficacious: a further analysis of the Dutch Bone Metastasis Study controlling for the influence of retreatment. Int J Radiat Oncol Biol Phys 59:528-537, 2004

40. Vincent Rajkumar S: Multiple myeloma: 2014 Update on diagnosis, risk-stratification, and management. Am J Hematol 89:999-1009, 2014

41. Wang XS, Rhines LD, Shiu AS, Yang JN, Selek U, Gning I, et al: Stereotactic body radiation therapy for management of spinal metastases in patients without spinal cord compression: a phase 1-2 trial. Lancet Oncol 13:395-402, 2012

42. Zhao H, Shi Q, Sun ZY, Gu QL, Ni L, Yang HL: The impor- tance of percutaneous vertebroplasty and radiation therapy for pathological vertebral compression fractures secondary to multiple myeloma. Arch Orthop Trauma Surg 132:16691670,2012

\section{Disclosures}

Dr. Suh has received travel and lodging expenses from Elekta.

\section{Author Contributions}

Conception and design: Angelov, Miller, Balagamwala. Acquisition of data: Miller, Balagamwala, Emch. Analysis and interpretation of data: Angelov, Miller. Drafting the article: Angelov, Miller. Critically revising the article: all authors. Reviewed submitted version of manuscript: all authors. Approved the final version of the manuscript on behalf of all authors: Angelov. Study supervision: Angelov.

\section{Supplemental Information \\ Previous Presentations}

Portions of this work were presented in abstract form at the 2014 Annual Meeting of the American Society for Radiation Oncology, San Francisco, California, September 14-17, 2014.

\section{Correspondence}

Lilyana Angelov, Rose Ella Burkhardt Brain Tumor and NeuroOncology Center, Desk S73, Taussig Cancer Institute, Cleveland Clinic, 9500 Euclid Ave., Cleveland, OH 44195. email: angelol@ ccf.org. 